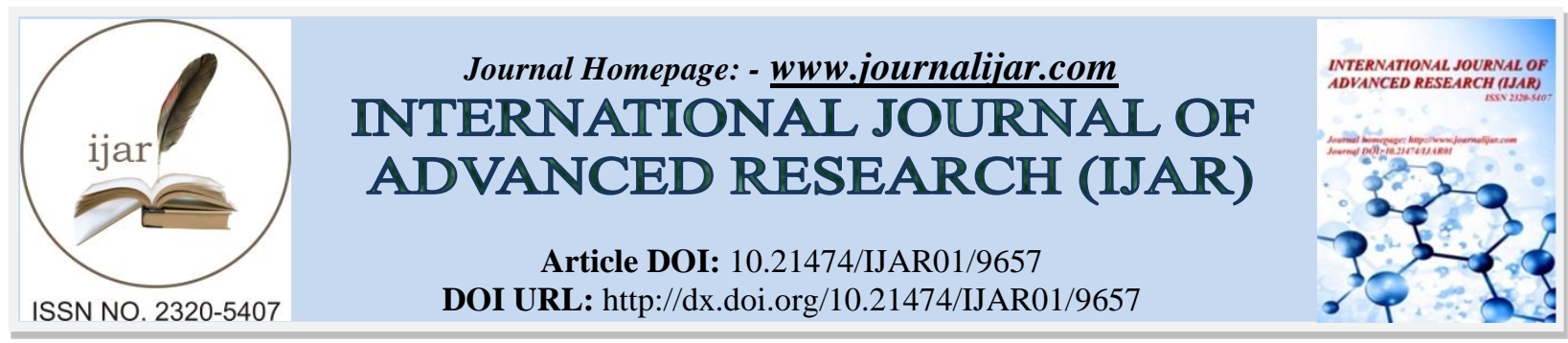

RESEARCH ARTICLE

\title{
AWARENESS OF DENTAL STUDENT ABOUT FACIAL PARALYSIS FOLLOWING INFERIOR ALVEOLAR NERVE BLOCK IN KSA.
}

\author{
Abdullah M Albejadi, Sofyan Saleh, Nada M Alhussain, Faleh A Alshahrani, Syed Sirajul Hassan, Maha M \\ Alshehri and Mohammed Alkindi.
}

\section{Manuscript Info}

Manuscript History

Received: 04 July 2019

Final Accepted: 06 August 2019

Published: September 2019

\section{Abstract}

\section{Introduction:-}

Administration of local anesthesia is a routine procedure of daily practice in dentistry.

The attainment of adequate analgesia in the operating field is necessary in order to achieve a fully cooperation with the patient and complete the treatment successfully ${ }^{1}$. However when administering regional anesthesia, performing per apical and dental implant surgeries, or implementing endodontic treatments in the mandible, it is important to anatomical variation and anatomical landmark to localize IAN and prevent injuries².

One of the most local analgesia complications of an inferior alveolar nerve block anesthesia is Facial nerve palsy. Facial nerve CN (VII) is the seventh paired cranial nerve derivatives of the second pharyngeal arch. Facial nerve anatomical is very complex there are many branches, which transmit a compilation of sensory, motor and parasympathetic fiber ${ }^{2}$.

Facial nerve palsy defines as a loss of facial muscles control due to injury or inflammation of facial nerve and it can be unilateral or bilateral. After injury occurrence to the facial nerve by any reason the facial muscles showing weakness or drooping. Accurately localizing inferior alveolar nerve is important when administering local anesthesia and performing dental treatment therefore, knowing the normal range of the possible locations is essential.

\section{Aim}

Our purpose of this study was to find out the knowledge of dental student toward the facial nerve paralysis after inferior alveolar nerve anesthesia in Saudi Arabia.

\section{Materials and Method:-}

This study was carried out in king Saudi Arabia, Faculty of Dentistry. Necessary approval from authorities was taken. A well-designed questionnaire was used to collect data from 250 dental student .130 they were males and 120 were females. Total responses from all dental students. Design the questionnaire survey using Google Forms, in addition to the tables that have been organized and analyzed. "Responses to our questions are organized automatically and systematically into forms, with real-time response plans and information, and better utilizing our data by looking at spreadsheets. The questionnaire involved the age, sex and address of student and many questions related to facial nerve paralysis diagnosis, clinical features, and management.. 


\section{Statistical methods:-}

After data were extracted, were revised, coded and fed to statistical software IBM SPSS version 22. All statistical analysis was done using two tailed tests and alpha error of 0.05 . P value less than or equal to 0.05 considered to be statistically significant. Descriptive analysis based on frequency and percent distribution was done for all categorical data (frequency tables). As for awareness, each correct answer given score of 1 point, otherwise zero score was given for the participant. All discrete awareness items scores were summed and then categorized into poor for those who had score less than $50 \%$ of the maximum score, moderate for those who had score ranged between $50 \%$ to less than $75 \%$ and others who had score exceeding $75 \%$ was considered of good awareness level. Univariant relations between the sample bio demographic characteristics and their awareness level were tested using Pearson chi square test.

\section{Results:-}

A total number of 250 questionnaires were sent to various departments of dental college in KSA. Among the 250 dental students, 130 samples $52 \%$ were male and 120 samples $48 \%$ were female. Most of samples age range from (20 to 26) years.

The results obtained were shown in Table 1 .

\begin{tabular}{|lcc|}
\hline \multicolumn{2}{|c|}{ Table (1): personal data of sampled dental students, Saudi Arabia } \\
\hline Personal data & No & $\%$ \\
\hline Age in years & & \\
$20-$ & 60 & $24.0 \%$ \\
$23-$ & 150 & $60.0 \%$ \\
$25+$ & 40 & $16.0 \%$ \\
\hline Gender & & \\
Male & 130 & $52.0 \%$ \\
Female & 120 & $48.0 \%$ \\
\hline
\end{tabular}

Awareness of dental students regarding facial palsy diagnosis methods, Saudi Arabia 
The results obtained were shown in Table 2 .

\begin{tabular}{|c|c|c|c|}
\hline Which type of facial paralysis is more common & $\begin{array}{l}\text { Immediate type } \\
\text { Delayed type }\end{array}$ & $\begin{array}{l}155 \\
95\end{array}$ & $\begin{array}{l}62.0 \% \\
38.0 \%\end{array}$ \\
\hline \multirow{4}{*}{$\begin{array}{l}\text { Maximum recovery duration of immediate type of facial } \\
\text { paralysis is }\end{array}$} & 1 hour & 37 & $14.8 \%$ \\
\hline & 2 hours & 97 & $38.8 \%$ \\
\hline & 3 hours & 57 & $22.8 \%$ \\
\hline & 4 hours & 59 & $23.6 \%$ \\
\hline \multirow{4}{*}{ Delayed type of facial paralysis start } & After $1 \mathrm{~h}$ & 44 & $17.6 \%$ \\
\hline & Several hours to several days & 141 & $56.4 \%$ \\
\hline & After 2 weelcs & 41 & $16.4 \%$ \\
\hline & After 1 month & 24 & $9.6 \%$ \\
\hline \multirow{4}{*}{ Which of this is not branch of facial nerve } & Zxapuatic nerve & 57 & $22.8 \%$ \\
\hline & Temporal nerve & 84 & $33.6 \%$ \\
\hline & Maxillary nerve & 68 & $272 \%$ \\
\hline & Mandibulax nerve & 41 & $16.4 \%$ \\
\hline \multirow{4}{*}{$\begin{array}{l}\text { Which technical mistake during LANB can result in } \\
\text { facial paralysis }\end{array}$} & Inject too posterior & 135 & $54.0 \%$ \\
\hline & Inject too superior & 62 & $24.8 \%$ \\
\hline & Inject too inferior & 30 & $12.0 \%$ \\
\hline & Short injection & 23 & $92 \%$ \\
\hline \multirow{4}{*}{ All of this can cause facial paralysis after LANB except } & $\begin{array}{l}\text { Direct trauma to inferior } \\
\text { alveolar nerve by a needle }\end{array}$ & 68 & $27.2 \%$ \\
\hline & Hematoma formation. & 77 & $30.8 \%$ \\
\hline & $\begin{array}{l}\text { Toxic damage due to local } \\
\text { anesthetics }\end{array}$ & 46 & $18.4 \%$ \\
\hline & Intra parotid injection & 59 & $23.6 \%$ \\
\hline \multirow{4}{*}{$\begin{array}{l}\text { Which of the following local anesthesia contents agent } \\
\text { has greater chance to cause facial paralysis }\end{array}$} & I.idhcaine & 68 & $272 \%$ \\
\hline & Bupixacaine & 77 & $30.8 \%$ \\
\hline & Mepixacaine. & 51 & $20.4 \%$ \\
\hline & Procaine & 54 & $21.6 \%$ \\
\hline \multirow{3}{*}{$\begin{array}{l}\text { Facial paralysis considers as complication of Waxisani- } \\
\text { Akinosi nerve block }\end{array}$} & No & 55 & $22.0 \%$ \\
\hline & Yes & 129 & $51.6 \%$ \\
\hline & Don't know & 66 & $26.4 \%$ \\
\hline \multirow{3}{*}{ Deviation of normal anatomy may cause facial paralysis } & No & 60 & $24.0 \%$ \\
\hline & Yes & 134 & $53.6 \%$ \\
\hline & Don't kcnow & 56 & $22.4 \%$ \\
\hline \multirow{3}{*}{ Intemal carotid artery has related to delayed facial palsy } & No & 57 & $22.8 \%$ \\
\hline & Yes & 85 & $34.0 \%$ \\
\hline & Don't know & 108 & $432 \%$ \\
\hline \multirow{3}{*}{ Delayed type recover during months } & No & 55 & $22.0 \%$ \\
\hline & Yes & 114 & $45.6 \%$ \\
\hline & Don't know & 81 & $32.4 \%$ \\
\hline
\end{tabular}

Table 3:-Dental students' awareness regarding facial palsy management methods, Saudi Arabia.

\begin{tabular}{|c|c|c|c|}
\hline Facial palsy management items & & No & 90 \\
\hline \multirow{4}{*}{ What is the main drug for facial paralysis patient } & Steroid & 146 & 5849 \\
\hline & Amoxicillin & 22 & $8.8 \%$ \\
\hline & Tbuprofen & 34 & $13.6 \%$ \\
\hline & Nitrous oxide & 48 & $192 \%$ \\
\hline \multirow{4}{*}{$\begin{array}{l}\text { What is the lst step in managentent of facial paralys is } \\
\text { after IANB }\end{array}$} & Re anesthetizing & 17 & $6.8 \%$ \\
\hline & Give him antibiotic & 19 & $7.6 \%$ \\
\hline & Reassure patient & 159 & $63.6 \%$ \\
\hline & $\begin{array}{l}\text { O Stop treatment and give } \\
\text { him another appointment }\end{array}$ & 55 & $22.0 \%$ \\
\hline \multirow{3}{*}{$\begin{array}{l}\text { Is it contraindicated to the doctor to re anesthetizing } \\
\text { patient to achieve mandible block }\end{array}$} & No & 75 & $30.0 \%$ \\
\hline & $Y=s$ & 115 & $46.0 \%$ \\
\hline & Don't know & 60 & $240 \%$ \\
\hline \multirow{3}{*}{$\begin{array}{l}\text { Artificial tears should be used with facial paralys is } \\
\text { patient }\end{array}$} & No & so & $20.0 \%$ \\
\hline & $Y=s$ & 128 & $512 \%$ \\
\hline & Don't know & 72 & $28.8 \%$ \\
\hline \multirow{3}{*}{$\begin{array}{l}\text { I ubrication of the eye is used to managernent facial } \\
\text { paralysis patient }\end{array}$} & No & 49 & $19.6 \%$ \\
\hline & Yes & 142 & $56.8 \%$ \\
\hline & Don't kcnow & 59 & $23.6 \%$ \\
\hline \multirow{3}{*}{$\begin{array}{l}\text { Contact lens should be removed from patient eye after } \\
\text { facial paralysis occurs }\end{array}$} & No & 37 & $148 \%$ \\
\hline & Yes & 149 & $59.6 \%$ \\
\hline & Don't kcnow & 64 & $25.6 \%$ \\
\hline \multirow{3}{*}{ Shouldn't usesunglasses with facial paralysis patient } & No & 100 & $40.0 \%$ \\
\hline & $Y=s$ & 57 & $22.8 \%$ \\
\hline & Don't kcnow & 93 & $372 \%$ \\
\hline
\end{tabular}


Table 4:-Dental students' awareness regarding facial palsy clinical features, Saudi Arabia.

\begin{tabular}{|c|c|c|c|c|c|c|}
\hline \multirow{2}{*}{ Facial palsy clinical features } & \multicolumn{2}{|c|}{ No } & \multicolumn{2}{|c|}{ Yes } & \multicolumn{2}{|c|}{ Don't know } \\
\hline & No & $\%$ & No & $9 \%$ & No & $\%$ \\
\hline Swelling of affected side & 105 & $42.0 \%$ & 87 & $34.8 \%$ & 58 & $23.2 \%$ \\
\hline Insbility to close the ayelids & 36 & $14.4 \%$ & 173 & $69.2 \%$ & 41 & $16.4 \%$ \\
\hline $\begin{array}{l}\text { Drooping of the comer of the } \\
\text { mouth }\end{array}$ & 40 & $16.0 \%$ & 168 & $67.2 \%$ & 42 & $16.8 \%$ \\
\hline $\begin{array}{l}\text { Deviation of the mouth toward the } \\
\text { affected side }\end{array}$ & 59 & $23.6 \%$ & 154 & $61.6 \%$ & 37 & $14.8 \%$ \\
\hline Trismugs. & 63 & $25.2 \%$ & 144 & $57.6 \%$ & 43 & $17.2 \%$ \\
\hline $\begin{array}{l}\text { Generalized weakness of affected } \\
\text { side }\end{array}$ & 58 & $23.2 \%$ & 156 & $62.4 \%$ & 36 & $14.4 \%$ \\
\hline Tearing of affected side & 92 & $36.8 \%$ & 109 & $43.6 \%$ & 49 & $19.6 \%$ \\
\hline
\end{tabular}

Figure 1:-Awareness level of dental students regarding facial palsy following Inferior Alveolar Nerve Block in KSA.

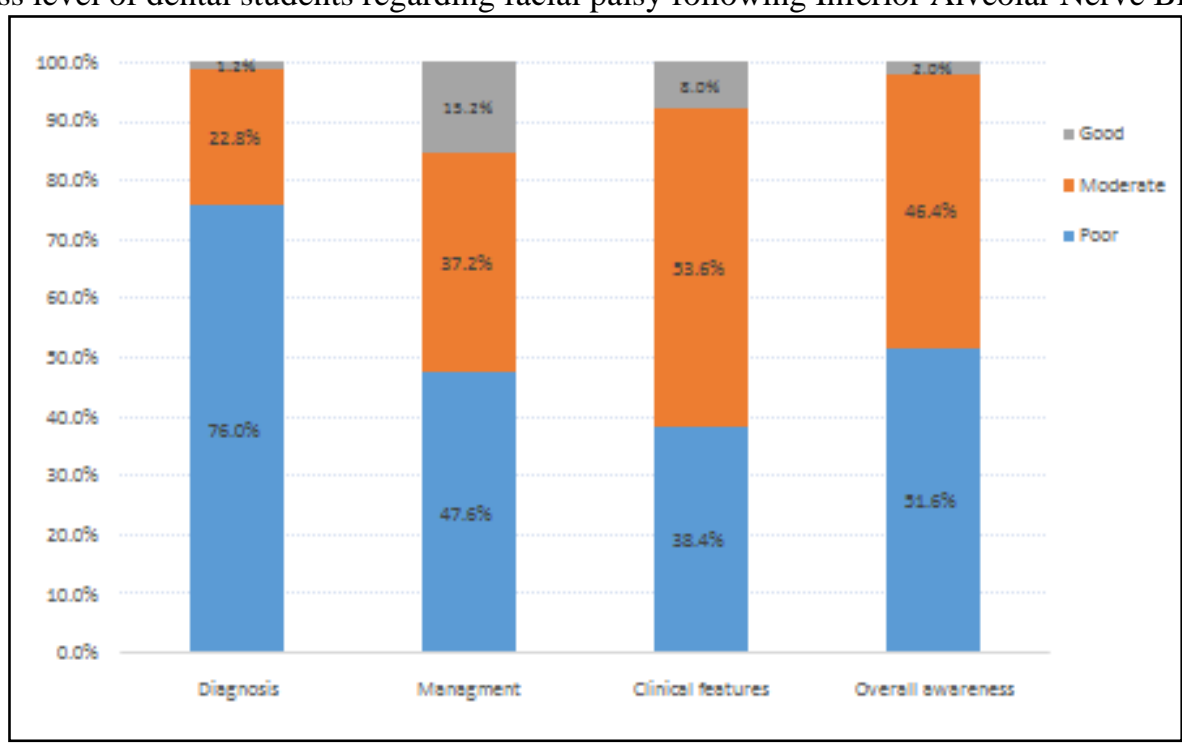


Table 5:-Awareness level of dental students regarding facial palsy following Inferior Alveolar Nerve Block in KSA by their age.

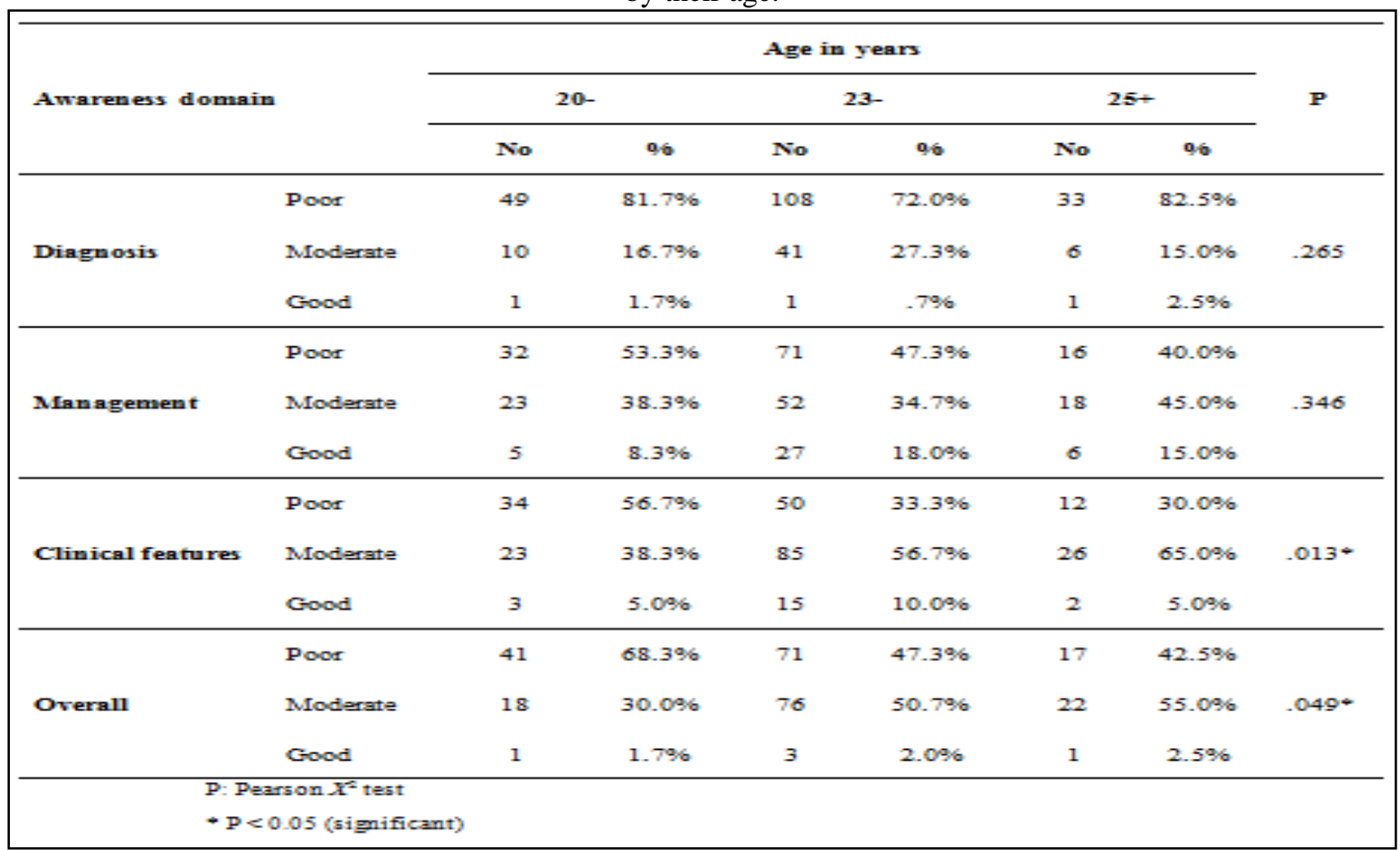

Table 6:-Awareness level of dental students regarding facial palsy following Inferior Alveolar Nerve Block in KSA by their gender.

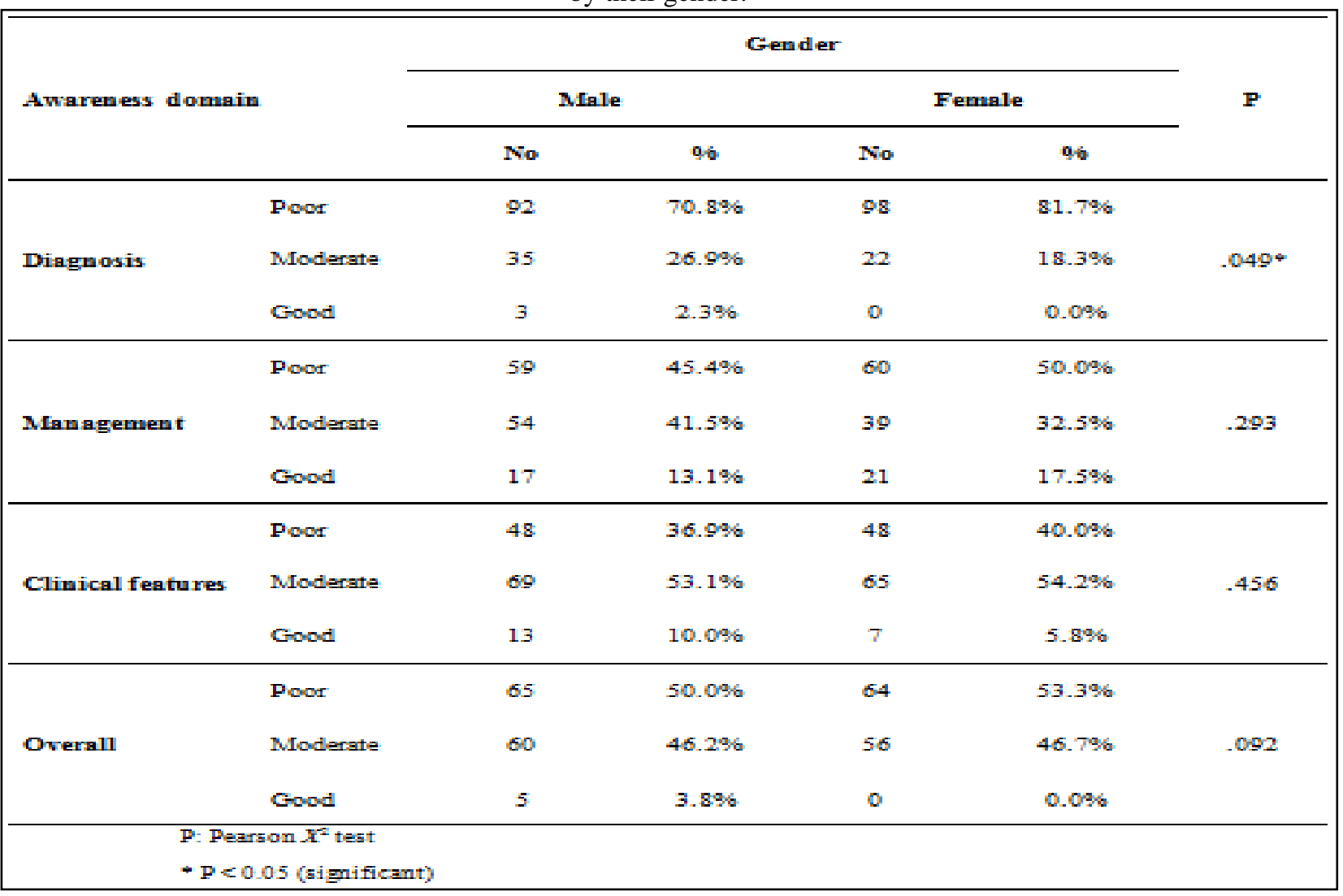




\section{Discussion:-}

Lack of success in obtaining complete anesthesia in dentistry may be related to anatomical, physiological or psychological factors. Anatomical variations at the site of the injection, infection or inflammation at the injection site and medical or psychological problems with which the patient may present, can affect the anesthetic outcome (patient related factors).

This study was designed to compare knowledge of dental student with other various levels toward the facial nerve paralysis after inferior alveolar nerve anesthesia and reassure the patient if it occur also to teach the students anew technique to avoid the FNP.

It was noticed that there was a significant lack of knowledge among undergraduate students and dental interns toward the facial nerve paralysis after inferior alveolar nerve anesthesia.

\section{Conclusion:-}

In dental practice, it should be considered that iatrogenic factors may play a direct or indirect role in FNP. The participants were generally unaware of most of the complications occurred after local anesthesia.

\section{THE AUTHORS:-}

1. Abdullah M Albejadi, Dental Intern, King Khaled University, Abha, Saudi Arabia

2. Sofyan Salih, Assistant Professor OMFS, King Khaled University, Abha, Saudi Arabia

3. Nada M Alhussain, Resident, Department of Oral and maxillofacial, King Khaled University, Abha, Saudi Arabia

4. Faleh A Alshahrani, Oral and maxillofacial Consultant, King Fahad Medical City, Riyadh, Saudi Arabia

5. Syed Sirajul Hassan, Assistant Consultant, Oral And Maxillofacial Surgery. King Fahad Medical City, Riyadh, Saudi Arabia.

6. Maha M Alshehri, Dental Intern, King Khaled University, Abha, Saudi Arabia

7. Mohammed Alkindi, Associate Professor \& Chairman, Department of Oral \& Maxillofacial Surgery, Faculty of Dentistry, King Saud University. Riyadh, Saudi Arabia.

\section{References:-}

1. https://www.ncbi.nlm.nih.gov/pmc/articles/PMC3309298/

2. Gupta T. Localization of important facial foramina encountered in maxillo-facial surgery. Clin Anat. 2008 Oct;21(7):633-40. [PubMed]

3. Ramoglu M, Demirkol M, Aras MH, Ege B. Peripheral Facial Nerve Paralysis Triggered by Alveolar Osteitis. J Craniofac Surg 2015;26:e292-3.

4. Finsterer J. Management of peripheral facial nerve palsy. Eur Arch Otorhinolaryngol 2008;265:743-52.

5. Pogrel MA, Bryan J, Regezi J. Nerve damage associated with inferior alveolar nerve blocks. J Am Dent Assoc 1995;126:1150-5.

6. Miles PG. Facial palsy in the dental surgery. Case report and review. Aust Dent J 1992;37:262-5.

7. Vasconcelos BC, Bessa-Nogueira RV, Maurette PE, Carneiro SC. Facial nerve paralysis after impacted lower third molar surgery: A literature review and case report. Med Oral Patol Oral Cir Bucal 2006;11:E1758. 